\title{
Angiotensin I converting enzyme genotype affects ventricular remodelling in children with aortic coarctation
}

\author{
M Zadinello, G Greve, X Q Liu, J R Barbosa Jr, I Schulze-Neick, J L Wilkinson, A N Redington
}

Heart 2005;91:367-368. doi: 10.1136/hrt.2003.026716

A ortic coarctation is a common abnormality comprising about $6 \%$ of congenital heart diseases. The narrowing of the aorta and consequent increased peak systolic stress is a potent stimulus for the development of left ventricular (LV) hypertrophy before repair. Clinically, however, the degree of hypertrophy and the progression to dilation and failure is variable. The extent of remodelling after successful repair is also difficult to predict, and persistence of hypertrophy has been demonstrated. Angiotensin converting enzyme (ACE) is responsible for the hydrolisation of angiotensin I into angiotensin II, which is the principal circulating hormone of the renin-angiotensin system. It was shown that angiotensin II stimulates myocardial growth by a direct effect on cardiac myocytes (increasing the fractional rate of protein synthesis), and also by indirect effects (increasing total peripheral vascular resistance). A single polymorphism of the ACE gene is described as follows: the insertion/larger allele, I, and the deletion/shorter allele, D, as well as a heterozygous form, ID, were located in intron 16 of chromosome 17q23. DD was associated with an increased plasma ACE activity and a high concentration of plasma angiotensin II. $^{1}$ ACE gene polymorphism has been implicated in the pathogenesis of various cardiovascular diseases. DD has been associated with LV hypertrophy, ischaemic and idiopathic cardiomyopathy, and an increased risk of sudden death in hypertrophic cardiomyopathy. ${ }^{2}$ This association between increased LV mass and ACE gene polymorphism might be expected to modify the responses to congenital abnormalities, but to date no data are available. This study examines the relation between polymorphism of the ACE gene and LV remodelling in children after successful repair of aortic coarctation.

\section{METHODS}

Data were collected from two centres, Royal Brompton Hospital \& Harefield NHS Trust, London, UK and Royal Children's Hospital, Melbourne, Australia. The inclusion criteria were as follows: children with isolated aortic coarctation, who were operated on during the first year of life, with no previous re-intervention, no signs of recoarctation (Doppler or arm/leg gradient $<20 \mathrm{~mm} \mathrm{Hg}$ at rest) and no resting hypertension. Children with bicuspid aortic valve without aortic valve stenosis (peak gradient $<10 \mathrm{~mm} \mathrm{Hg}$ by Doppler) were included. Ethical approval and informed consents were obtained.

Bio samples were obtained either from $1 \mathrm{ml}$ of peripheral blood using a Nucleon kit (Nucleon Biosciences) or from buccal swabs using a MasterAmp buccal swab DNA extraction kit (Epicentre Technologies). The genotype for each sample of ACE gene was determined by polymerase chain reaction (PCR). The polymorphism is the presence or absence of a 300 base pair DNA fragment. PCR detects a 190 base pair fragment (deletion), and a 490 base pair (insertion). PCR products were separated by electrophoresis and visualised by ethidium bromide staining.
Measurements of the echocardiographic parameters interventricular septum in diastole (IVSd), posterior wall in diastole (PWd), and left ventricle in diastole ( $\mathrm{LVd})$, were determined according to the American Society of Echocardiography (ASE) convention. ${ }^{3}$ Each measurement was repeated three times and the average was used. Absolute diastolic mass was calculated using three different methods, the $\mathrm{ASE},{ }^{4}$ the adjusted ASE, ${ }^{5}$ and the ellipsoid relationship. ${ }^{6}$ The values were indexed by body surface area (BSA), BSA ${ }^{1.5}$, and height ${ }^{2.7}$. $^{5}$

Unpaired Student's $t$ test and a bimodal distribution were applied. Analysis of the three ACE genotypes was carried out as follows: II $v$ DD; II $v$ ID, and II $v$ ID + DD. A probability value of $\mathrm{p} \leqslant 0.05$ was considered significant.

\section{RESULTS}

Forty five patients (28 males) were enrolled in the study. Mean (SD) age at operation was 2.25 (3.25) months. Twenty five patients $(56 \%)$ had their operation within the neonatal period. Body weight at the time of surgery was 5 (2) kg; BSA was $0.24(0.08) \mathrm{m}^{2}$. Subclavian flap repair was performed in 36 patients $(80 \%)$; end to end anastomosis was performed in the remainder. Mean age at follow up was 7 (5) years. Mean follow up time was 7 (5.2) years.

Patients were grouped according to their ACE genotype. The genetic distribution was as follows: 14 patients had the II genotype (31\%), 22 patients had the ID genotype (49\%), and nine patients had the DD genotype (20\%).

Table 1 shows the results for diastolic ventricular mass (according to the three methods) adjusted for BSA, BSA ${ }^{1.5}$, and height ${ }^{2.7}$. DD genotype was associated with increased ventricular mass when compared with II genotype. There was no difference between II and ID. However, when the II group was compared with all those with D insertion (ID + DD), the LV mass adjusted by BSA was significantly increased.

\section{DISCUSSION}

This study shows a relation between genotype and LV phenotype in the setting of congenital heart disease. We have shown that the genotype significantly affects LV mass in patients after an uncomplicated repair of aortic coarctation. Postoperatively, no patient had important residual obstruction or associated lesions and none were receiving medication for resting hypertension. In these patients the possession of the D allele, particularly DD, was associated with increased LV mass. We chose to assess LV mass using multiple algorithms because of the lack of acceptance of individual methods. Despite different techniques, there was broad agreement between them, substantiating the presence of an

Abbreviations: ASE, American Society of Echocardiography; ACE, angiotensin I-converting enzyme; BSA, body surface area; IVSd, interventricular septum in diastole; LVd, left ventricle in diastole; LV, left ventricular; PCR, polymerase chain reaction; PWd, posterior wall in diastole 
Table 1 Left ventricular mass

\begin{tabular}{|c|c|c|c|c|c|c|}
\hline$t$ test & ASE & $p$ Value & ASE adjusted & $p$ Value & Wikstrand & p Value \\
\hline \multirow[t]{4}{*}{$\| v \mathrm{DD}$} & $\begin{array}{l}\text { ASE } \\
5725(36.83) \text { v } 84.38(32.42)\end{array}$ & 0.09 & $\begin{array}{l}\text { ASE adjusted } \\
46.40(29.47) \vee 68.11(25.94)\end{array}$ & 0.09 & $\begin{array}{l}\text { Wikstrand } \\
63.20(51.11) \text { v } 94.62(47.80)\end{array}$ & 0.16 \\
\hline & $\begin{array}{l}\text { ASE/BSA } \\
5729(13.78) \text { v } 78.09(1434)\end{array}$ & $0.002^{*}$ & $\begin{array}{l}\text { ASE adjusted BSA } \\
46.67(10.94) \text { v } 63.08\end{array}$ & $0.002^{*}$ & $\begin{array}{l}\text { Wikstrand BSA } \\
57.04(20.63) \text { v } 85.06(22.47)\end{array}$ & $0.01^{*}$ \\
\hline & $\begin{array}{l}\text { ASE/BSA } \\
64.50(22.42) \vee 77.40(17.42)\end{array}$ & 0.16 & $\begin{array}{l}\text { ASE adjusted/BSA } 1.5 \\
52.69(18.49) \text { v } 62.54 \text { (14.09) }\end{array}$ & 0.19 & $\begin{array}{l}\text { Wikstrand/BSA } \\
60.81 \text { (17.19) v } 83.20(20.14)\end{array}$ & $0.01^{*}$ \\
\hline & $\begin{array}{l}\text { ASE/height } \\
1.4 \times 10^{-4}\left(5.7 \times 10^{-5}\right) v \\
1.6 \times 10^{-4}\left(4.4 \times 10^{-5}\right)\end{array}$ & 0.43 & $\begin{array}{l}\text { ASE adjusted/height } \\
1.1 \times 10^{-4}\left(4.8 \times 10^{-5}\right) v \\
1.3 \times 10^{-4}\left(3.5 \times 10^{-5}\right)\end{array}$ & 0.48 & $\begin{array}{l}\text { Wikstrand/height } \\
1.3 \times 10^{-4}\left(3.9 \times 10^{-5}\right) v \\
1.7 \times 10^{-4}\left(4.8 \times 10^{-5}\right)\end{array}$ & $0.05^{*}$ \\
\hline \multirow[t]{4}{*}{$\| v \mid D$} & $\begin{array}{l}\text { ASE } \\
57.25(36.83) \vee 60.57(31.06)\end{array}$ & 0.77 & $\begin{array}{l}\text { ASE adjusted } \\
46.40(29.47) \vee 49.06(24.85)\end{array}$ & 0.77 & $\begin{array}{l}\text { Wikstrand } \\
63.20(51.11) \text { v } 64.46(42.05)\end{array}$ & 0.94 \\
\hline & $\begin{array}{l}\text { ASE/BSA } \\
57.29(13.78) \vee ~ 66.32(13.98)\end{array}$ & 0.07 & $\begin{array}{l}\text { ASE adjusted/BSA } \\
46.67(10.94) \text { v } 53.84(11.17)\end{array}$ & 0.07 & $\begin{array}{l}\text { Wikstrand/BSA } \\
57.04(20.63) \text { v } 67.01 \text { (18.85) }\end{array}$ & 0.15 \\
\hline & $\begin{array}{l}\text { ASE/BSA } \\
64.50(22.42) \vee 74.17(23.20)\end{array}$ & 0.23 & $\begin{array}{l}\text { ASE adjusted/BSA } \\
52.69(18.49) \vee 60.31(19.02)\end{array}$ & 0.24 & $\begin{array}{l}\text { Wikstrand/BSA } \\
60.81(17.19) \text { v } 72.92(18.82)\end{array}$ & 0.06 \\
\hline & $\begin{array}{l}\text { ASE/height } \\
1.4 \times 10^{-4}\left(5.7 \times 10^{-5}\right) v \\
1.6 \times 10^{-4}\left(7 \times 10^{-5}\right)\end{array}$ & 0.34 & $\begin{array}{l}\text { ASE adjusted/height } \\
1.1 \times 10^{-4}\left(4.8 \times 10^{-5}\right) v \\
1.3 \times 10^{-4}\left(5.7 \times 10^{-5}\right)\end{array}$ & 0.36 & $\begin{array}{l}\text { Wikstrand/height } t^{.7} \\
1.3 \times 10^{-4}\left(3.9 \times 10^{-5}\right) \mathrm{v} \\
1.6 \times 10^{-4}\left(5.5 \times 10^{-5}\right)\end{array}$ & 0.14 \\
\hline \multirow[t]{4}{*}{$\begin{array}{l}\| v \\
D D+I D\end{array}$} & $\begin{array}{l}\text { ASE } \\
57.25(36.83) \vee ~ 67.49(32.81)\end{array}$ & 0.36 & $\begin{array}{l}\text { ASE adjusted } \\
46.40(29.47) \vee 54.59(26.25)\end{array}$ & 0.36 & $\begin{array}{l}\text { Wikstrand } \\
63.20(51.11) \text { v } 73.22(45.17)\end{array}$ & 0.16 \\
\hline & $\begin{array}{l}\text { ASE/BSA } \\
57.29(13.78) \vee 69.73(14.87)\end{array}$ & $0.01^{*}$ & $\begin{array}{l}\text { ASE adjusted/BSA } \\
46.67(10.94) \text { v } 56.52(11.85)\end{array}$ & $0.01^{*}$ & $\begin{array}{l}\text { Wikstrand/BSA } \\
57.04(20.63) \text { v } 72.25(21.28)\end{array}$ & $0.03^{*}$ \\
\hline & $\begin{array}{l}\text { ASE/BSA } \\
64.50(22.42) \vee 75.11(21.44)\end{array}$ & 0.14 & $\begin{array}{l}\text { ASE adjusted/BSA } 1.5 \\
52.69(18.49) \vee 60.96(17.53)\end{array}$ & 0.16 & $\begin{array}{l}\text { Wikstrand/BSA } \\
60.81(17.19) \vee 75.91(19.45)\end{array}$ & $0.02^{*}$ \\
\hline & $\begin{array}{l}\text { ASE/height } \\
1.4 \times 10^{-4}\left(5.7 \times 10^{-5}\right) v \\
1.6 \times 10^{-4}\left(6.3 \times 10^{-5}\right)\end{array}$ & 0.30 & $\begin{array}{l}\text { ASE adjusted/height } \\
1.1 \times 10^{-4}\left(4.8 \times 10^{-5}\right) v \\
1.3 \times 10-4\left(5.1 \times 10^{-5}\right)\end{array}$ & 0.33 & $\begin{array}{l}\text { Wikstrand/height } 2.7 \\
1.3 \times 10^{-4}\left(3.9 \times 10^{-5}\right) v \\
1.6 \times 10^{-4}\left(5.3 \times 10^{-5}\right)\end{array}$ & 0.07 \\
\hline
\end{tabular}

Table shows methods of left ventricular mass calculation including American Society of Echocardiography (ASE) method, ASE method adjusted, and Wikstrand's method. The following units are used: body surface area (BSA) $\left(\mathrm{m}^{2}\right)$ and height $(\mathrm{cm})$.

*Denotes significance; all data are expressed as mean (SD).

important LV hypertrophic response. The importance of our findings lies in the potential influence of ACE genotype on adverse cardiovascular events.

Whether this represents failure of regression of a previous hypertrophic response or reflects an abnormal hypertrophic response in the setting of chronically abnormal haemodynamics, cannot be answered by our data. Most evidence would favour the latter. Despite adequate repair, endothelial function in the upper body is abnormal, and our own recent data suggest a persistently increased arterial stiffness in teenagers and adults. ${ }^{7}$

ACE genotype seems to influence the incidence of cardiac events independent of structural abnormalities (for example, cardiomyopathies). ${ }^{12}$ The combination of adverse ACE genotype and a haemodynamic stimulus may amplify these adverse effects. While speculative, knowledge of ACE genotype may identify or help to refine risk stratification in those at risk from long term cardiovascular morbidity. Furthermore, knowledge of genotype may increase understanding of the need for, and response to, treatment of resting, exercise or ambulatory hypertension, the management of which remains controversial in these patients.

In summary, this is the first study to demonstrate the influence of ACE genotype on ventricular phenotype in patients with congenital heart disease. Possession of the D allele, both in heterozygotes, but particularly homozygotes, predicts increased LV mass after successful repair of aortic coarctation. This may have important implications for the long term cardiovascular mortality in these patients.

\section{ACKNOWLEDGEMENTS}

Professor A Kessling (Northwick Park and St Marks NHS Trust, UK); Dr D du Sart, Dr M Delatycki (Murdoch Institute, RCH, Australia).

\section{Authors' affiliations}

M Zadinello*, X Q Liu, J L Wilkinson, Cardiology Department, Royal Children's Hospital, Melbourne, Australia
G Grevet, I Schulze-Neick, A N Redington, Royal Brompton \& Harefield NHS Trust, School of Medicine, Imperial College of Science, Technology and Medicine, London, UK

J R Barbosa Jr, Department of Chemical Engineering and Chemical Technology, Imperial College of Science, Technology and Medicine

*Also at Royal Brompton \& Harefield NHS Trust, School of Medicine, Imperial College of Science, Technology and Medicine, London, UK

†Also at Department of Heart Disease, Haukeland University Hospital, Bergen, Norway

A poster version of this manuscript was awarded a Best Paper Prize at the 18th Brazilian Congress of Pediatric Cardiology/10th Latin Congress of Pediatric Cardiology and Cardiovascular Surgery, 12-15 November 2003, Recife, Brazil.

Correspondence to: Professor Andrew N Redington, Division of Cardiology, Hospital for Sick Children, 555 University Avenue, Toronto, Ontario, Canada M5G 1X8; andrew.redington@sickkids.ca

Accepted 27 April 2004

\section{REFERENCES}

1 Schunkert $\mathbf{H}$. Polymorphism of the angiotensin-converting enzyme gene and cardiovascular disease. J Mol Med 1997:75:867-75.

2 Marian AJ, Yu QT, Greve G, et al. Angiotensin -converting enzyme polymorphism in hypertrophic cardiomyopathy and sudden cardiac death. Lancet 1993:342:1085-6.

3 Sahn DJ, DeMaria A, Kisslo J. Recommendations regarding quantification in M-mode echocardiography: results of a survey of echocardiographic measurements. Circulation 1978;58:1072-82.

4 Teichholz LE, Kreulen T, Herman MV, et al. Problems in echocardiographic volume determinations: echocardiographic-angiographic coprrelations in the presence or absence of asynergy. Am J Cardiol 1976;37:7-11.

5 de Simone G, Daniels SR, Devereux RB, et al. Left ventricular mass and body size in normative children and adults: assessment of allometric relations and impact of overweight. J Am Coll Cardiol 1992;20:1251-60.

6 Wikstrand J. Calculation of left ventricular mass in man - a comment. J Hypertens 1997;15:811-3.

7 de Divitiis $M$, Pilla $C$, Zadinello $M$, et al. Ambulatory blood pressure, left ventricular mass, and conduit artery function late after successful repair of coarctation of the aorta. J Am Coll Cardiol 2003;41:2259-65. 